\title{
Dynamic Complexity in a Keynesian Growth-Cycle Model Involving Harrod's Instability
}

\author{
Mario C. Sportelli
}

Received August 7, 1998; revised version received June 22, 1999

\begin{abstract}
This paper develops a Keynesian macrodynamic model, where some recent reinterpretations of Harrod's dynamics are embodied. Its main purpose is to prove that Harrod's "instability principle" may give rise to a chaotic motion (specifically a Šil'nikov scenario) around two equilibrium points: a steady-state unstable equilibrium, whose value depends on parameters defining the technical-progress dynamics, and a stationary state of zero growth. Furthermore, since it allows for a variable growth rate of labor productivity and assigns a key role to expectations, this model comes closer to modern theories of economic growth and endogenous business cycle.
\end{abstract}

Keywords: economic dynamics, chaotic fluctuations, business cycle, Harrod's dynamics.

JEL classification: $\mathrm{E} 12, \mathrm{E} 32, \mathrm{C} 62$.

\section{Introduction}

In recent years Harrod's dynamics have been reinterpreted as a theory aimed at the joint explanation of economic growth and the business cycle. This stimulating new interpretation emerges from the epistemological works by Besomi (1995; 1996; 1998a, b), Pugno (1992), Kregel (1980), and from the pioneering analytical contributions by Goodwin (1951) and Glombowski and Krüger (1982). Nevertheless, the well-known "knifeedge problem" introduced by Harrod is still perceived as a burden in Keynesian macrodynamic models (e.g., Flaschel et al., 1997, chap. 1). Different approaches are often used in these models to overcome (or to avoid) the "knife edge" (e.g., Goodwin's, 1967, class struggle, Kaldor's, 1940, 
interaction between savings and investments, or Rose's, 1967, nonlinearities). ${ }^{1}$

Our paper develops a Keynesian-type macrodynamic model aimed at demonstrating that the "instability principle" (which was always emphasized by Harrod himself) may give rise to a chaotic motion, through the dynamic interaction between Harrod's three famous rates of growth (i.e., the actual, warranted, and natural rates of growth). Specifically it yields a Šil'nikov scenario around two equilibrium points: a steady-state unstable equilibrium, whose value depends on parameters defining technical progress, and a stationary state of zero growth. Furthermore, the presence of a variable rate of labor-productivity growth and the key role played by expectations bring Harrod's macrodynamics closer to modern theories of economic growth and endogenous business cycle.

The paper is organized as follows. Section 2 restates a new analytical formalization of Harrod's basic model. The resulting system turns out to be under-determined, and Sect. 3 considers one possible way (the simplest) of completing the model. Then, a qualitative analysis of the resulting threedimensional system is provided. Section 4 concludes.

\section{A New View on Harrod's Macrodynamics}

It is well-known that Harrod's dynamic theory is a result of many works written over the period of his whole intellectual life. ${ }^{2}$ Some of them are replies to criticisms and additional explanations, often stimulated by formal models which misinterpreted his central and crucial idea about an "unstable" growth path which characterizes capitalist economies. Unfortunately, the results which emerge from inferential restatements of his basic "model" never successfully broadened the conclusions met by Harrod and the full-employment steady-state equilibrium theories prevailed. ${ }^{3}$

If we concentrate our attention on Harrod's (1948) book "Towards a Dynamic Economics," which is unanimously seen as the first complete and

1 For further details, see: Franke and Asada (1994), Choi (1995), Chiarella and Flaschel (1996).

2 See Pugno (1998, p. 152).

3 We include in this set of theories both the so-called post-Keynesian and neoclassical growth theories. As we know, the former bases the equilibrium on a variable average propensity to save depending on the distribution of income (e.g., Kaldor, 1955); the latter, on a flexible capital/product ratio deriving from a neo-classical production function (e.g., Solow, 1956; Swan, 1956). 
refined exposition of his theory, we find two fundamental peculiarities. The considerable literature which followed from Harrod's contributions, starting with Baumol $(1948,1949,1952)$, were never formalized in a satisfactory fashion. ${ }^{4}$ The peculiarities are: the instability principle and the dynamic role of technical progress.

To set out our exposition schematically, we begin by denoting the actual income rate of growth as $G$, the warranted rate as $G_{\mathrm{W}}$, and the natural rate as $G_{\mathrm{n}}$. Although Harrod's symbols are used, we would emphasize that here $G_{\mathrm{W}}$ will be interpreted as a variable rate of growth defined on the basis of entrepreneur's (rational) expectations ${ }^{5}$; and $G_{\mathrm{n}}$ as a variable and endogenous technical-progress rate of growth. Furthermore, let us remember that, in Harrod, $G \equiv \Sigma / C$ and $G_{\mathrm{W}} \equiv \Sigma / C_{\mathrm{r}}$, where $\Sigma$ is "the fraction of income saved" " $C$ "the increase in the volume of goods of all kinds outstanding at the end over that outstanding at the beginning of the period divided by the increment of production in that same period" (Harrod, 1948 , p. 78); $C_{\mathrm{r}}$ "the requirement for new capital divided by the increment of output to sustain which the new capital is required" (Harrod, 1948, p. 82).

\subsection{The Instability Principle}

On pages $85-87$ of his book, Harrod clearly explains his "instability principle," comparing a given $G_{\mathrm{w}}$ with the current $G$. Harrod writes " $\ldots$ if the value $G$ is above that of $G_{\mathrm{w}}$, the value of $C$ must be below that of $C_{\mathrm{r}}$; there will be insufficient goods in the pipe-line and/or insufficient equipment, and order will be increased." On the contrary, if $G<G_{\mathrm{W}}$ it must be that $C>C_{\mathrm{r}}$ and there will be an excess supply of goods in the pipeline and/or over productive capacity in the economic system. Here it is crucial to avoid the mistake of considering $C$ (or $C_{\mathrm{r}}$ ) as a traditional technical-accelerator coefficient. ${ }^{7}$ As we said above, $C$ denotes the ratio of additional goods "of all kinds" to the production increase carried out at a given time. This means that $C$ (in its numerator) includes both new equipment and addi-

4 See the famous Hahn and Matthews (1964) survey.

5 A similar interpretation has been already adopted by Hahn (1990, p. 23), to characterize $G_{\mathrm{W}}$ as a perfect-foresight equilibrium, and, incidentally, by King and Robson (1992, p. 44).

6 We do not use the usual $s$ to avoid the impression that the share of income saved is assumed constant.

7 Explicitly, on page 84 Harrod points out that " $C_{\mathrm{r}} \ldots$ may not be equal to the capital coefficient in the economy as a whole." 
tional stocks. The definition of $C_{\mathrm{r}}$ is similar. In fact, Harrod himself states that capital means in his treatment "both equipment and stock-in-trade" (p. 85). Unlike $C, C_{\mathrm{r}}$ is the ratio of desired additional goods to the expected production increase based on entrepreneurs' previous expectations. Therefore, assuming that total output $(Y)$ carried out at a given period derives from a given expected demand $\left(Y^{\mathrm{e}}\right),{ }^{8}$ let us denote the increase in the volume of goods (ex post investment) as $I$, the increase in production ${ }^{9}$ as $\dot{Y}$, the requirement for new capital as $I_{\mathrm{j}}$ (justified investment) and, finally, the expected production (demand) increase as $\dot{Y}^{\mathrm{e}}$. Thus, we can simply write $C=I / \dot{Y} ; C_{\mathrm{r}}=I_{\mathrm{j}} / \dot{Y}^{\mathrm{e}}$. Now according to Harrod's reasoning we can state the following implications and inequalities:

$$
G>G_{\mathrm{w}} \Longrightarrow C<C_{\mathrm{r}} \Longrightarrow\left\{\begin{array}{l}
I<I_{\mathrm{j}} \\
\text { or } \\
\dot{Y}>\dot{Y}^{\mathrm{e}} .
\end{array}\right.
$$

Noting that all the inequalities will be reversed when $G<G_{\mathrm{w}}$ and that the implications' sequence seems to be reversible in any case, we can see that if $C_{\mathrm{r}}$ were a constant, centrifugal forces working around the expected line of advance should reduce (increase) $C$ further and further in comparison with $C_{\mathrm{r}}$, when the inequality $G \gtrless G_{\mathrm{W}}$ is assumed to persist along a given sequence of periods. ${ }^{10}$ Since $C$ (unlike $C_{\mathrm{r}}$ ) is an observable and measurable quantity, clearly this conclusion contrasts with Romer's (1989) view based on empirical data: in the long run the capital/output ratio shows a tendency to remain constant. ${ }^{11}$ If a "tendency" to be constant means that this ratio may change inside a bounded interval (which can be arbitrarily small), the theoretical inconsistency of a continuously decreasing (increasing) $C$ can be demonstrated simply. ${ }^{12}$

Let $K$ be the capital stock in the Harrod sense and $v=K / Y$ the capital/ output ratio. Differentiation of $v$ with respect to time yields (after some

8 In other words, we assume an economy governed by the effective-demand principle.

9 From now on, a dot over the variable will indicate the operator $\mathrm{d} / \mathrm{d} t$ and continuous time will be assumed.

10 In fact, when $G \neq G_{\mathrm{W}}$, there will not be any tendency to adapt production towards $G_{\mathrm{W}}$, but a tendency to adapt production still further away from it (Harrod, 1939, 1948, respectively, p. 14 and p. 87).

11 This "stylized fact" was already described by Kaldor (1961).

12 Note that the assumption of a constant $C$ is equally inconsistent. $C_{\mathrm{r}}$ should move away from $C$ indefinitely, thus losing its economic meaning. 
rearrangement):

$$
\dot{v}=\frac{\dot{Y}}{Y}\left(\frac{I}{\dot{Y}}-\frac{K}{Y}\right)=G(C-v) .
$$

This result does not need any particular comment, but it allows us to realize the remarkable difference between Harrod's own time scale and the usual notion of "long run," characterizing growth models. Harrod's approach to dynamic theory is founded on the concept of "long period" which pertains to the typical industrial trade cycle. The "long period" is much less than the "long run" and, according to the particular phase of the cycle, substantial differences between $I / \dot{Y}$ and $K / Y$ may be observed. Sudden increases or cuts in inventories with respect to the slower change in productive capacity may have some influence on these differences. ${ }^{13}$ Therefore, given $G \neq 0$, only alternate changes in the sign of $(C-v)$ over time will be consistent with an average $v$, whose value tends to be stable.

Having rejected the implications of a constant $C_{\mathrm{r}}$, we can now explain those centrifugal forces working in a disequilibrium condition on the basis of firms' rational reactions to a difference $G-G_{\mathrm{W}}>0 .{ }^{14}$

In every period $t$ entrepreneurs' investment decisions are made on the basis of an expected change in demand $\dot{Y}^{\mathrm{e}}$. Therefore, ex ante investment $I_{\mathrm{j}}$ (justified by $\dot{Y}^{\mathrm{e}}$ ) will be:

$$
I_{\mathrm{j}}=C_{\mathrm{r}} \dot{Y}^{\mathrm{e}}
$$

If ex post it turns out that $\dot{Y}>\dot{Y}$, then effective investment $(I)$ will be less than ex ante $I_{\mathrm{j}}$, because stocks are below the desired level. This is equivalent to saying that the actual desired capital coefficient $C_{\mathrm{r}}$ (in Harrod's sense) has become greater than the actual $C$. So that if capacity utilization is near full levels, each firm will decide on new investments, first to restore stock levels and, secondly, to increase, if necessary and profitable, its productive capacity to make it consistent with new levels of production. This implies an increase in $I$ (at least in inventories only), which will work in its turn for a new $\dot{Y}$ according to the monotonic multiplier effect. It follows that a new $C$ will be progressively attained in the course of the period. ${ }^{15}$

13 Further details are in Harrod (1936, chap. 2).

14 On p. 89 of his 1948 book, Harrod himself affirms that $G_{\mathrm{W}}$ may change in the "trade cycle". Given his own definition of $G_{\mathrm{W}}$, this implies both $\Sigma$ and $C_{\mathrm{r}}$ cannot be constants.

15 Let us note that the new value of $C$ exactly reflects Harrod's definition quoted above. 
According to our reasoning, nothing leads us to predict changes in the aggregate levels of $I$ and $Y$ such as to generate a constant value of $C$, in the system. Our reasoning instead points out that an increase in $C_{\mathrm{r}}$ may drag slowly (or, alternatively, with a lag) $C$ on the rise. ${ }^{16}$ Now, if we assume that in each period firms are careful to acquire any new information generated by the system to forecast future demand, then the new (the current) $Y^{\mathrm{e}}$ will surely differ from its past value. This happens because agents' rational behavior requires that an erroneous expectation must be changed. Compared with the perceived current level of demand, the new $Y^{\mathrm{e}}$ enables firms to define the actual $\dot{Y}$ e. If this value is positive, as will be the case in a period of rising business activity, a new amount of investments will be justified, according to Eq. (1).

It should be noticed here that there are points of similarity between our approach and Fazzari's (1985), and Pugno's (1998, pp. 162-166) microeconomic assumptions regarding a firm's behavior in disequilibrium conditions. Both these authors critically discuss the strong hypothesis of the Rational-Expectation Theory ${ }^{17}$ in a Keynesian perspective. They show that non-market-clearing assumptions and a decentralized decision process, interwoven with standard rational-expectation arguments, reinforce instability in the system, rather than the convergence to equilibrium. This result is founded on firms' reactions, to the inequality $\dot{Y} \gtrless \dot{Y}^{\mathrm{e}}$, similar to the ones we assume. Nevertheless, our reasoning is more general for at least two reasons. First, no constant parameter (like $C, C_{\mathrm{r}}$, or $\Sigma$ ) constrains our arguments and therefore no explosive divergence between $\dot{Y}$ and $\dot{Y}^{\mathrm{e}}$ can be perceived a priori. Secondly, here firms' behavior and their reactions to disequilibrium are developed in continuous time, which allows us to emphasize some peculiarities of the motion often lost by formalizations in discrete time.

Let $\dot{Y}^{\mathrm{e}}>0$ be the actual expected change in demand and assume it to be greater than its previous value. Under these hypotheses the new $I_{\mathrm{j}}$ in Eq. (1) will be more than its previous value. In other words, by assuming a positive $\dot{Y}^{\mathrm{e}}$, justified investments will evolve according to the following derivative:

$$
\dot{I}_{\mathrm{j}}=\dot{C}_{\mathrm{r}} \dot{Y}^{\mathrm{e}}+C_{\mathrm{r}} \ddot{Y}^{\mathrm{e}}
$$

16 Time lags in Harrod's trade-cycle theory are well discussed by Besomi $(1998 a, b)$.

17 Agents know the "model", so that incorrect expectations will be modified systematically and stable equilibria will be reached or restored. 
where the first term on the right-hand side can be interpreted as stock investments filling existing storehouse gaps and the latter term, as additional goods, aimed at restoring actual stock levels to sustain the new $\dot{Y}^{\mathrm{e}}$ and, if necessary and profitable, the new equipment required by the change in $\dot{Y}^{\mathrm{e}}$. When a sequence of positive (nondecreasing) $\ddot{Y}^{\mathrm{e}}$ persists along a given time path, the $I_{\mathrm{j}}$ dynamics will be accelerated and the distance between $I$ and $I_{\mathrm{j}}$ itself may be increased. This is due to the fact that $I$ follows $I_{\mathrm{j}}$, but, realistically with a sticky motion, since investments involving the productive capacity cannot be carried out instantaneously.

Now it is crucial to point out that when $I_{\mathrm{j}}$ is pushed forward to $I, C_{\mathrm{r}}$ is pushed ahead of $C$ and if $I_{\mathrm{j}}$ accelerates, there will be a large gap between $C_{\mathrm{r}}$ and $C$. Recalling our initial assumption $\dot{Y}>\dot{Y}^{\mathrm{e}}$, we can infer that the run for $C_{\mathrm{r}}$ is path dependent on the gap $\dot{Y}-\dot{Y}^{\mathrm{e}}$ and that the greater this difference is, the more violent the thrust forward of $C_{\mathrm{r}}$ will be.

We may interpret the $C_{\mathrm{r}}$ path dependence as an intrinsic component of Harrod's instability principle. Furthermore, we are able to state that the $C_{\mathrm{r}}$ motion does not lead the difference between $C$ and $C_{\mathrm{r}}$ itself to be inevitably explosive. Looking at Eq. (2), it is plain that, if $\ddot{Y}$ e becomes negative, as will certainly happen sooner or later, the sign of $\dot{I}_{\mathrm{j}}$ may change. Consequently, the growth of $C_{\mathrm{r}}$ will slow down initially, and its value may decrease as soon as $I$ exceeds $I_{\mathrm{j}} .{ }^{18}$ Hence, changes in the value of $C$ (which follows $C_{\mathrm{r}}$ ), will be bounded over time, according to Romer's empirical result.

\subsection{An Important Implication of the Dynamic Process}

We noted that $I<I_{\mathrm{j}}$ implies an increase in $I$, which will entail, during the given period, a new $\dot{Y}$. If we assume a sequence of periods such that $I_{\mathrm{j}}-I>0$ always holds, then, according to our reasoning, a sequence of positive $\dot{Y}$ will ensue. Furthermore, if the distance between $I_{\mathrm{j}}$ and $I$ increases in every period, then a sequence of rising $\dot{Y}$ may drive $G$ on the rise. This is because increasing inventory gaps together with additional equipment orders lead all the firms to accelerate their production rates. ${ }^{19}$

Looking at the wide variety of literature inspired by Harrod's theory, our conclusion seems to be similar to Alexander's (1950) explanation of the instability principle. We would notice here that the Alexander approach

18 Sooner or later, productive-capacity increases resulting from firms' optimistic foresights will exceed the desired levels.

19 This confirms that implications (R. H.) are reversible. 
was unique and received, though with some criticism, an explicit approval by Harrod (1951, p. 263). So, in accordance with Alexander, if we define as $U$ the difference between $I_{\mathrm{j}}$ and $I$ (i.e., $U=I_{\mathrm{j}}-I$ ), given Eq. (1), and the ex post identity $I=$ aggregate saving, we can write:

$$
U=C_{\mathrm{r}} \dot{Y}^{\mathrm{e}}-\Sigma Y,
$$

i.e.,

$$
u=\frac{U}{Y}=C_{\mathrm{r}} \frac{\dot{Y}^{\mathrm{e}}}{Y}-\Sigma .
$$

As we explained above, unlike Harrod, we define $G_{\mathrm{w}}=\dot{Y} \mathrm{e} / Y$. Therefore we can state the following:

Postulate 1: Let $T$ be a time interval. If, $\forall t \in T, I_{\mathrm{j}} / Y$ exceeds $I / Y$, then along $T$, the growth of produced income will undergo acceleration. On the contrary, if $I / Y$ exceeds $I_{\mathrm{j}} / Y$, then along $T$, the growth of income will undergo deceleration.

Given that (by definition) $G \equiv \dot{Y} / Y$ and given $u \gtreqless 0$, Postulate 1 can be stated in equation form as ${ }^{20}$

$$
\dot{G}=f(u),
$$

such that $\dot{G} \gtreqless 0$ if $u \gtreqless 0$. Furthermore, we shall assume $0<f^{\prime}<1$ as an additional consequence of the stickiness affecting the investment component which involves changes in the level of the productive capacity.

For simplicity, if the function $f(u)$ is assumed to be linear, we can write

$$
\dot{G}=\alpha\left(C_{\mathrm{r}} G_{\mathrm{w}}-\Sigma\right)
$$

where $0<\alpha<1$ denotes the sensitivity of $\dot{G}$ with respect to changes in the gap $\left(I_{\mathrm{j}} / Y-I / Y\right)$. Since here, according to our reasoning, $C_{\mathrm{r}}$ is a variable whose value increases when the difference $\left(\dot{Y}-\dot{Y}^{\mathrm{e}}\right)$ increases, we can set, without altering the relationship structure, $C_{\mathrm{r}}=\Phi\left(G-G_{\mathrm{W}}\right)$. This is possible because, given the inequalities (R. H.), the inequality $\dot{Y}-\dot{Y}^{\mathrm{e}} \gtreqless 0$ is a consequence (and a cause) of $G-G_{\mathrm{w}} \gtreqless 0$.

The function $\Phi$ will be subject to the following formal and logical assumptions: i) $\Phi^{\prime}>0$; ii) $\Phi(0)=C^{*}$, because $G=G_{\mathrm{w}}$ (or $\dot{Y}=\dot{Y}^{\mathrm{e}}$ ) implies $I_{\mathrm{j}}=I$ and thus $C_{\mathrm{r}}$ will be equal to its equilibrium value $C^{*}$ when the actual demand change is exactly that, on average, what firms expected.

20 This equation can be found in Alexander (p. 728) where discrete time is assumed. 
Given the function $\Phi$, Eq. (4) becomes

$$
\dot{G}=\alpha\left[\Phi\left(G-G_{\mathrm{w}}\right) G_{\mathrm{w}}-\Sigma\right] .
$$

Equation (5) confirms that growth will be in a steady state if and only if $I_{\mathrm{j}} / Y=I / Y=\Sigma$, i.e., when $G=G_{\mathrm{w}}$. In this case there is no acceleration in $\dot{Y}$ and, therefore, $\dot{G}=0$. It follows that

$$
\Phi(0) G_{\mathrm{W}}-\Sigma=0 \Longrightarrow G_{\mathrm{w}}=\frac{\Sigma}{C^{*}}=G,
$$

according to Harrod's conclusions.

It is now interesting to note that:

i. since $\Sigma$ (i.e., $I / Y$ ) is an unknown quantity in this equation, the value of $\Sigma$ making $G$ consistent with $G_{\mathrm{W}}$ is not unique. In other words, this means that (transient) multiple equilibria may exist between realized production and foreseen demand levels;

ii. unlike Alexander's approach, our Eq. (5) may imply $\dot{G}=0$ also when $G \neq G_{\mathrm{w}}$.

In both cases, of course, additional assumptions about $G_{\mathrm{w}}$ and $\Sigma$ would be necessary to describe the dynamics of $G$.

Furthermore, we have to point out that Harrod's definition of $G_{\mathrm{w}} \equiv \Sigma$ / $C_{\mathrm{r}}$ is inconsistent with our Eq. (4), since $\dot{G}$ would always be equal to zero. Nevertheless, Alexander's own instability formalization reflects Harrod's notion of the warranted rate of growth. In fact, Harrod defines $G_{\mathrm{W}}$ as the growth rate of production equating, at a given time, savings and ex ante investments (Harrod, 1939, p. 19). When inequalities between these quantities subsist, $G$ will change as Alexander (1950, p. 728) postulated, according to Harrod's reasoning.

The problem of inconsistency in our version of Alexander's equation arises from the difference between Harrod's and our definition of $G_{\mathrm{w}}$. As shown by Besomi (1998, pp. 51-53), several ambiguities are contained in Harrod's warranted rate of growth. Mainly they concern the improper use of the term ex ante attached to investments together with the attempt to solve the problem of the consistency between a single-agent equilibrium and a macroeconomic notion of equilibrium. ${ }^{21}$

Our Eq. (4) gives rise to none of these problems: ex ante investment is justified by expected demand change $\left(\dot{Y}^{\mathrm{e}}\right) ; G_{\mathrm{w}}$ is the expected rate of

21 This problem had been already posed by Harrod in The Trade Cycle (1936, chap. 2). 
change of aggregate demand. Unlike Harrod, who defines ex ante (or justified) the equilibrium amount of investments, the former assumption is conformable to the conventional usage because it is concerned with investment decisions. The latter is the result of underlying processes in the expectation formation. Nonetheless, according to Harrod, our $I, C, Y, \dot{Y}$, and, therefore, $G$ are all interlocked quantities and, in Harrod's words, "determined from time to time by trial and error, by the collective trial and error of vast numbers of people" (Harrod, 1948, p. 86). When firms' expectations are satisfied $G=G_{\mathrm{w}}$, but this "equilibrium" (which may not be unique) has nothing to do with the dynamic equilibrium of the economy.

\subsection{The Key Role of the "Natural Rate of Growth" and the Saving-Rate Dynamics}

As we know steady-state equilibrium is independent of full employment in the system. It only ensures the consistency between expected and actual demand changes (i.e., $\dot{Y}^{\mathrm{e}}$ and $\dot{Y}$ ). Employment-level changes are strictly connected with the labor force and technical-progress dynamics. In other words, over time employment levels yielded by the system deals with Harrod's "natural rate of growth" $G_{\mathrm{n}}$, i.e., "the rate of advance which the increase of population and technological improvements allow" (Harrod, 1948, p. 87).

Here, unlike Harrod, our $G_{\mathrm{n}}$ neglects the contribution resulting from population growth. This is because Harrod's long period is a time scale where population changes scarcely affect the labor force and, we add, taking into account modern growth theories, the human-capital formation slightly enhances available labor input. Thus, our $G_{\mathrm{n}}$ will be interpreted exclusively as a rate of growth in the average productivity of labor. As we shall see later, the generality of Harrod's theory is not affected by this assumption.

Beginning on page 87, Harrod (1948) considered the effects on growth coming from a divergence between $G_{\mathrm{n}}$ and $G_{\mathrm{W}}$. In the first place Harrod observes that " $G_{\mathrm{n}}$ sets a limit to the maximum average value of $G$ over a long period"; secondly, he states that "the relation of $G_{\mathrm{n}}$ and $G_{\mathrm{w}}$ is ... of crucial importance in determining whether the economy" will be prevalently "lively or depressed." If $G_{\mathrm{n}}>G_{\mathrm{w}}$ "there is no reason why $G$ should not exceed $G_{\mathrm{w}}$ " (Harrod, 1948, p. 88). Therefore, an expansion process can be started. Conversely, "since the average value of $G$ over a period cannot exceed that of $G_{\mathrm{n}}$," if $G_{\mathrm{n}}<G_{\mathrm{w}}$, the value of $G$ will be prevalently below $G_{\mathrm{w}}$ and consequently the economy will be depressed. 
This latter conclusion seems a paradox because, at first sight, "one would suppose it to be a good thing that the line of entrepreneurial contentment should be one implying an attempt to push forward always at a greater rate than fundamental conditions allow" (Harrod, 1948, p. 88), i.e., than the rate of growth $G_{\mathrm{n}}$ allows. But, Harrod says, "analysis reveals the opposite to be the case."

This is an obscure passage in Harrod's account, and one that growth theorists usually interpreted in a simplistic fashion. In fact, as we know, given an exogenous $G_{\mathrm{n}}$, either variability in $\Sigma$ - due to changes in income distribution (Kaldor, 1955, 1956) - or variability in $C$ - derived from a neo-classical production function (Solow, 1956; Swan, 1956) - make the steady-state equilibrium stable. With regard to these results, we would point out that in successive stages Harrod contested the neo-classical approach and the term "knife-edge" attached to his equilibrium condition by Solow (1956, p. 65), ${ }^{22}$ but he did not even sympathize with the post-Keynesian approach. This is because Kaldor's assumption on flexible prices with respect to money wages eliminated the instability problem completely, making the full-employment steady-state path a natural condition which economies tend towards.

In order to explain the "paradox", aggregate savings are considered by Harrod. He states: "saving is a virtue and beneficial so long as $G_{\mathrm{W}}$ is below $G_{n}$. While it is disastrous to have $G_{\mathrm{W}}$ above $G_{\mathrm{n}}$, it is not good to have it too far below ...," because "plenty of booms and a frequent tendency to approach full employment ... will be of an inflationary and thereby unhealthy character. In these circumstances saving is a virtue since, by raising $G_{\mathrm{W}}$, it enables us to have good employment without inflation. But if $G_{\mathrm{w}}$ is above $G_{\mathrm{n}}$, saving is a force making for depression" (Harrod, 1948, pp. 88f.).

These reflections by Harrod lead us to distinguish explicitly between the level of saving $(S)$ and the saving/income ratio $(\Sigma=S / Y)$. Somewhat confused in the Harrod statement quoted above, this distinction has a crucial importance in understanding how saving may fit into a dynamical framework while remaining consistent with Harrod's view. ${ }^{23}$

Preliminarily, we must point out that changes in the level of savings may

22 See Harrod (1973, p. 33). We have to notice here that Solow adopted the term "knife-edge" in referring to the divergence between $G_{\mathrm{W}}$ and $G_{\mathrm{n}}$. Instead, it was interpreted by Harrod as referred to the divergence between $G$ and $G_{\mathrm{W}}$. Further details on this problem are in Besomi (1998, pp. 58-61).

23 "Dynamics ... deals ... with the effects of continuing changes and with rates of change in the values that have to be determined" (Harrod, 1948, p. 8). 
imply a different rate of saving if either a constant value of income is a priori assumed, or if it happens that $S$ is rising (reducing) quicker than $Y$ during a given time interval. Furthermore, without any reference to $C_{\mathrm{r}}$ or $C$, a value of $S$ that increases $\Sigma$ may increase both $G_{\mathrm{W}}$ and $G$, in accordance with Harrod's own definitions of these two variables. ${ }^{24}$ Therefore, at the height of an expansion, although the distance between $G_{\mathrm{n}}$ and $G_{\mathrm{w}}$ may be altered, the distance between $G_{\mathrm{w}}$ and $G$ might not be. Thus, an inflationary process should be sharpened rather than slackened.

To deal correctly with this question, we have to consider the speed at which $S$ is rising (falling) when the income level is changing.

Let us begin by looking at the level of aggregate saving at a given time $t$. We have no way to cut off the desired level of $S$ and concentrate our attention on the undesired component. According to agents' rational behavior, we are only able: i) to know that the desired component is a fraction of the income level people hold as normal, or at least satisfactory, to sustain the current welfare level subjectively chosen; ii) to predict that an expected income increase may drive the desired level of $S$ upwards, without altering the value of $\Sigma$; while an unexpected income increase raises, at least in the short run, prevalently the undesired component of $S$. Hence, the $\Sigma$ value may show the tendency to increase. iii) Finally, we know that both expected and unexpected income reductions will primarily give rise to a saving drop rather than a cut in consumption. However, unexpected income reductions may be such as to reduce the $\Sigma$ value.

From a macroeconomic point of view, taking into account that uncertainty prevails in the world, all these considerations suggest that when income is changing, the elasticity of aggregate saving with respect to income shows the tendency to be, for the most part and surely whenever $G \neq G_{\mathrm{W}}$, more than one, rather than equal to one. ${ }^{25}$ It follows that the rate of change of saving will be prevalently higher than the rate of change of income and, therefore, the savings rate will be inclined "to vary with a change in the size of income, but" - as Harrod states (1939, p. 25) "a change in the rate of growth at a given point of time has no effect on

24 Here we refer to the Harrod definitions quoted in the 1939 paper and in the 1948 book. Harrod explicitly considers a desired rate of saving $\left(s_{\mathrm{d}}\right)$ to define $G_{\mathrm{W}}$, in the 1973 book. There, the treatment of discrepancies between actual and desired saving rate is very similar to the one concerned with deviations between $C$ and $C_{\mathrm{r}}$. Reasons dealing with changes in the current saving ratio, however, remain unclear.

25 In this latter case, $\Sigma$ should be a constant, because of $\dot{S} / S=\dot{Y} / Y$. Furthermore, marginal and average propensity to save should have an equal value. 
its size." If this conclusion is true, we need an explanation able to make clear why, in the different phases of the cycle, $\Sigma$ varies independently of the changes $G$ may undergo.

Given agents' rational decisions on saving, we can postulate, according to Harrod's intuitions $(1939$, p. 21), that the elasticity of aggregate saving is inclined: i) to rise above one whenever the level of unexpected profits (and, in general, of income) show the tendency to become abnormally large; ii) to decline (approaching one) whenever profits (or incomes) show the tendency to move around the level firms (people) perceive as satisfactory; iii) to rise again, moving away from one, when profits (or incomes) fall under the level perceived as satisfactory. The former case implies an increasing $\Sigma$, because $S$ increases quicker than $Y$; the latter case implies a falling $\Sigma$, because $S$ decreases more quickly than $Y$; the middle case implies a fairly steady value of $\Sigma$. All this enables us to suppose a dependence of $\Sigma$ changes on the difference $G_{\mathrm{n}}-G_{\mathrm{W}}$. If, for simplicity, this dependence is assumed to be linear, we can write:

$$
\dot{\Sigma}=\varepsilon\left(G_{\mathrm{n}}-G_{\mathrm{w}}\right),
$$

where $\varepsilon>0$ is a parameter denoting the sensitivity of $\dot{\Sigma}$ to the divergence between productivity and the dynamics of expectations.

This is because swifter productivity increases, with respect to changes in expected income, yield higher firms' profit margins, and consequently (independently of Kaldor's distribution theory) tend to increase either the saving firms' use of self-finance investments, or the dividend distributed to shareholders or both. The result will be a rise of $\Sigma$. In contrast, a slower productivity change, with respect to changes in expected income, reduces $\Sigma$.

Now, if we consider Eq. (5) again and assume $G_{\mathrm{n}}>G_{\mathrm{w}}$, we can see that Eq. (6) implies $\dot{\Sigma}>0$, so that the rise of the actual growth rate will tend to slow down. Even though this result is consistent with the "effective-demand principle", it seems to be in contrast with Harrod's viewpoint, which considered increases in $\Sigma$ as beneficial to the system when $G_{\mathrm{n}}>G_{\mathrm{w}}$. Near full-employment conditions, Harrod's viewpoint is certainly correct, because a decelerated growth depresses the rate of inflation, but what happens when this is not the case?

This question would remain a puzzle without some further brief details provided by Harrod himself. He writes: "Even if saving as a fraction of income is fairly steady in the long run, it is not likely to be so in the short run. There is some tendency for saving in the short period to be a residual 
between earnings and normal habits of consumption.... Thus even if $G_{\mathrm{W}}$ is normally below $G_{\mathrm{n}}$, it may rise above it in the later stages of an advance, and, if it does so, a vicious spiral of depression is inevitable when full employment is reached" (Harrod, 1948, p. 89).

Clearly the property "fairly steady" ascribed to $\Sigma$ should be a logical contradiction if it were interpreted as "absolutely steady". ${ }^{26}$ In the first place, Harrod (1948, p. 79) himself stated that "saving as a fraction of income might not be constant." Secondly, as formally expressed by Eq. (5) (approved by Harrod), the "instability principle" should be simply an algebraic tool aimed at checking the discrepancies between $I_{\mathrm{j}} / Y$ and $\Sigma$ and so to predict changes in $G$. In fact, if $\Sigma$ were a constant, Harrod's instability would simply coincide with the mathematical notion of dynamic instability. Notice that Alexander $(1950$, p. 729$)$ was the first who gave prominence to this point. However, as his reasoning was bound to the constancy ${ }^{27}$ of $\Sigma$ and $C_{\mathrm{r}}$, he contradicts himself by interpreting the instability in the sense meant by Harrod with the mathematical notion of instability. That is why we choose here to interpret "fairly steady" in a more correct and consistent way with Harrod's ideas as "moderately variable in the long run."

Let us note that our Eq. (6) reflects this interpretation properly; given $\varepsilon$, discrepancies between $G_{\mathrm{n}}$ and $G_{\mathrm{W}}$ might be so wide as to generate some major changes in $\Sigma$ only by coincidence. Normally, both $G_{\mathrm{n}}$ and $G_{\mathrm{w}}$ change in the different phases of the cycle, and the sign of their algebraic difference may vary, even though in itself this difference might be very small. This allows us to state that our Eq. (6) is able to describe long-run motion of the savings rate, because its effective value is inclined to change over time in the neighborhood of its mean value.

Now we only need to look for an explanation of benefits linked with the savings-rate behavior when $G_{\mathrm{n}}>G_{\mathrm{w}}$, but an inflationary process is not in progress. Next, we shall face the question raised by the different behavior of saving in the short and long run.

We feel that empirical evidence on growth and business-cycle theories can be of assistance in understanding the savings-rate puzzle.

Empirical evidence shows that average labor productivity is somewhat procyclical and leads the cycle (Kydland, 1995, p. 128), i.e., productivity

26 Up to now this seems to have been the interpretation prevailing in the literature.

27 In fact, constancy of $\Sigma$ is sufficient to make mathematically instable $G$ dynamics. As it will be possible to verify, our model would be able to exhibit only a saddle point as a steady-state equilibrium if $\Sigma$ were a constant. 
shows a tendency to rise (to decrease) early and faster with respect to real income. ${ }^{28}$ Therefore, if in Eq. (6) we think of a decelerating $G_{\mathrm{n}}$ near the height of an expansion so that it goes down relatively to a rising $G_{\mathrm{W}}$, then the expansion will be sustained with a reduction of $\Sigma$. However, according to Harrod, when $G_{\mathrm{w}}$ exceeds $G_{\mathrm{n}}$, independently of the reached employment level, sooner or later $G$ will fall below $G_{\mathrm{W}}$ and a slump will be inevitable. ${ }^{29}$

Finally, in regard to the fairly different behavior of $\Sigma$ in the short run relative to the long run, we think that our Eq. (6) needs to be modified to make the dynamics of $\Sigma$ more consistent with the tendency of saving to be a residual between income and consumption in the short run. A possible way to explain this phenomenon is by means of the hysteresis which affects the level of saving in the short run. In fact, positive (negative) effects on savings levels deriving from high increases (reductions) of income along a given period may not be suddenly reversed in subsequent periods. Some memory of past shocks is likely to remain in every period. For this reason, Eq. (6) has been extended by adding a hysteresis effect. So that, a further element dealing with the particular phase of the cycle in the economy is taken account of. Therefore we shall write:

$$
\dot{\Sigma}=\varepsilon\left(G_{\mathrm{n}}-G_{\mathrm{W}}\right)+\delta \dot{G}_{\mathrm{W}},
$$

where $\delta>0$ is a hysteresis parameter whose value will be assumed to be large enough for $\dot{G}_{\mathrm{W}}$ to have a meaningful direct effect on $\dot{\Sigma}$. This is because the value of $\dot{G}_{\mathrm{W}}$ will never be too high in any single period.

The hysteresis in the savings-rate dynamics may be justified as follows. Firms (people) show the tendency to increase their desired fraction of income saved more quickly in a period of rising business activity, in line with optimistic expectations on the future demand (income) level. Conversely, in a period of falling business activity, in line with pessimistic expectations, firms (people) are less inclined to save. Now, if we assume a value of $\varepsilon$ inside a not too large neighborhood of one, the level of $\Sigma$ will never be excessively affected by changes deriving from the evolving $\left(G_{\mathrm{n}}-G_{\mathrm{W}}\right)$, but it will be suddenly modified according to the sign and the size of $\dot{G}_{\mathrm{W}}$. Therefore, as expressed by Eq. (7), the $\Sigma$ dynamics enable us to distinguish

28 Details about this argument can be found in econometric works by Bean (1990), Stadler (1990), Saint-Paul (1993), Malley and Muscatelli (1995).

29 Note that at the end of his 1939 paper (p. 33), Harrod himself mentions the possibility that the economic system may "relapse into depression before full employment is reached in the boom." But, unlike Harrod, we ascribe the slump to a slowing down $G_{\mathrm{n}}$ and not exclusively to a rising $G_{\mathrm{W}}$. 
a long-run sluggish motion from different short-run shocks dealing with agents' changeable expectations.

There is no other Harrodian or, in general, Keynesian macrodynamic model using this type of dynamic equation to formalize the cyclical motions of the savings rate.

Works by Glombowski and Krüger (1982,pp. 137f.) and, more recently, by Pugno (1998, p. 160) perceive the importance of a variable $\Sigma$. Their models improved many old formalizations of Harrod's dynamics, because they overcome the instability concept meant as explosive motion. In fact, by means of a variable average propensity to save, the former gives rise to a Liénard equation able to display (as it is well-known) a stable limit cycle, i.e., regular cycles around the steady-state equilibrium. ${ }^{30} \mathrm{By}$ considering discrete time dynamics, the latter follows the Harrod outline of the 1973 book (p. 36), and distinguishes normal from abnormal business conditions. When normal business conditions prevail, the system evolves with a constant savings rate and fixed capital/output ratio. Conversely, when abnormal business conditions are in progress, the savings rate and the capital/output ratio change quickly. As a result, the economy will experience a nearly steady growth phase under normal business conditions, while the cycle will replace growth, when business conditions become abnormal. ${ }^{31}$

Our approach further improves the results reached by these models. In the first place, it is to be observed that our equation for the savings rate is theoretically founded, unlike the Glombowski and Krüger function. Furthermore, although Harrod (1939, pp. 24f.) explicitly said that the average propensity to sāve is independent of the values of $G$ and $\dot{G}$, these authors (p. 138) consider $\Sigma$ as exclusively dependent on $G$ and $\dot{G}$. In addition, the savings-rate variability is explained by our Eq. (7) without invoking the Kaldor distribution theory. On the contrary, the adjustment process suggested by Pugno (p. 160) is founded on this assumption. We should remind the reader that Harrod never shared Kaldor's conclusions.

\section{Completion of the Model and Qualitative Analysis}

Taking Eqs. (5) and (7) together, we can see that our view on Harrod's macrodynamics leads to a basic model, which is more complex than the

30 Note that the flexible-accelerator model by Goodwin (1951) already used the Liénard equation to describe the Harrodian trade cycle.

31 Analytically, the dynamics in this model are described by using an "unconventional" Rössler type attractor. 
ones which Keynesian and neo-classical growth theorists have suggested to date. Furthermore we have to point out that our basic model is only an under-determined dynamical system. ${ }^{32}$ It might be considered as a starting point to build a general mathematical model able to describe the cyclical growth mechanism of an economic system.

Here we choose the simplest way to complete the model by making reference to a closed economy without a public sector. Then we carry out a formal study of its dynamic properties.

\subsection{The Expected (Warranted) Rate of Growth $G_{\mathrm{W}}$}

Earlier we defined $G_{\mathrm{w}}=\dot{Y}^{\mathrm{e}} / Y$. Now we need to specify its dynamics formally. Noting that Harrod himself (1948, p. 89) explicitly states that " $G_{\mathrm{W}}$ fluctuates in the trade cycle," from a general point of view, we might define the $G_{\mathrm{w}}$ over-time behavior either by means of a backward-looking or forward-looking variable, or a combination of them (e.g., Turnovsky, 1995, chap. 1). Yet, our choice of a simple laissez-faire economy does not allow us to opt here for a more realistic and general hypothesis. ${ }^{33}$ Therefore, we assume that the expected rate of change of demand is a continuous function defined as a weighted average of all past rates of change of effective demand, i.e.,

$$
G_{\mathrm{w}}=\int_{-\infty}^{t} \frac{1}{T} \mathrm{e}^{-(1-\tau) / T} G \mathrm{~d} \tau
$$

$T$ is the mean time lag, which assigns more or less weight to past values of $G$. By periodic checks of their stocks (at least once in a period), firms are able to infer the actual level changes of demand. Therefore, we suppose a reaction lag for $G_{\mathrm{w}}$ such that $T \leq 1$.

Differentiation of Eq. (8) yields:

$$
T \dot{G}_{\mathrm{W}}+G_{\mathrm{W}}=G .
$$

32 Two equations include four unknowns.

33 In this version of the model there are typically no forward-looking economic variables. These are treated, in modern macrodynamic theories, as jump variables because of their instantaneous response to new information. For details, see Turnovsky (1995). 


\subsection{The Desired Capital Coefficient $C_{\mathrm{r}}$ (in the Sense of Harrod)}

In Sect. 2.2 we defined the function $C_{\mathrm{r}}=\Phi\left(G-G_{\mathrm{w}}\right)$ such that $\Phi^{\prime}>0$, $\Phi(0)=C^{*}$. Now, for simplicity, we shall assume a linear approximation of $\Phi$. Therefore, we write:

$$
C_{\mathrm{r}}=C^{*}+\varphi\left(G-G_{\mathrm{w}}\right),
$$

where $C^{*}$ is the equilibrium value of $C_{\mathrm{r}}$ and $\varphi>0$ is a parameter measuring the sensitivity of $C_{\mathrm{r}}$ to the difference $\left(G-G_{\mathrm{w}}\right)$.

We shall assume that $\varphi$ is sufficiently large to ensure meaningful changes in $C_{\mathrm{r}}$ for any given change in $\left(G-G_{\mathrm{w}}\right)$ whose (absolute) value cannot be realistically too high in a single period. Furthermore, since the $C_{\mathrm{r}}$ dynamics cannot be independent of $G_{\mathrm{w}}$, we assume that the smaller $T$ is (i.e., the greater $1 / T$ is), the higher will the sensitivity of $C_{\mathrm{r}}$ be. In other words, the parameter $\varphi$ will be considered the higher the greater the speed of $G_{\mathrm{W}}$ adjustment to past levels of $G$ (i.e., $1 / T$ ).

\subsection{The Natural Rate of Growth $G_{\mathrm{n}}$}

Following King and Robson $(1992,1993)$, we shall assume that the technical progress takes the form of "learning by watching". This is because new ideas are embodied in investment projects realized by one firm (or industry) and these generate externalities for other firms (or industries), which are able to learn from these ideas and adapt them for their own business. In other words, the learning-by-watching hypothesis is an extension of the Arrow (1962) learning by doing, where technological knowledge is treated as a public good. Although this last assumption raised some criticism (e.g., Romer, 1986, 1990), because knowledge is often lacking in complete nonrivalry and nonexcludability characteristics, Cohen and Levinthal (1989), and recently Offerman and Sonnemans (1998) have shown empirically that many innovations in one firm or industry have originated in developments in other firms or industries. Therefore, assuming that investments create a spillover effect, we consider a technical-progress function relating "the rate of growth of productivity to the proportion of economic activity that takes the form of new investment projects" (King and Robson, 1993, p. 59), i.e., the rate of investment. The qualitative nature of the technical-progress function remains unchanged when its argument is aggregate net investment or gross investment,${ }^{34}$ here, according to Harrod's investment concept, we

34 See King and Robson (1993, p. 61) for details. 
have no difficulty in assuming our effective (ex post) rate of investment as an argument of the technical-progress function. So that, given the equality $I / Y=\Sigma$, we can write:

$$
G_{\mathrm{n}}=F(\Sigma) .
$$

According to King and Robson's theoretical considerations, we can think of the function $F$ as nonlinear. Nevertheless, we do not adopt their assumption that $F$ should be a logistic curve. Although it is truncated at the origin of the axes, the logistic function exhibits an asymptote as the least upper bound of its codomain. If this property of the function is realistically justifiable by the existence of an upper bound of the growth rate $G_{\mathrm{n}}$, we cannot ignore that unity is the least upper bound of the investment (savings) rate. Furthermore, it is logically inadmissible to think that $G_{\mathrm{n}}$ may be still rising when $I / Y$ (i.e., $\Sigma$ ) is near to one, i.e., when the consumption rate is close to zero.

For these reasons we shall suppose the function $F$ has the following formal property: $\exists \bar{\Sigma}<1$, i.e., $\bar{I} / Y<1$, such that $F(\bar{\Sigma})$ is a local maximum. This means that the productivity rate of growth will rise only when the investment rate, i.e., the savings rate, is below $\bar{\Sigma}$. But if $\Sigma$ exceeds $\bar{\Sigma}$, the productivity rate of growth will decline because accelerated decreasing returns and an insufficient expansion of consumption are forces making for slackening productivity dynamics. $\bar{\Sigma}$ may be interpreted as an optimum savings rate (investment rate) from a social-welfare point of view.

To allow our model to be mathematically tractable, the function $F$ has been specified as a one-hump type function, i.e.,

$$
G_{\mathrm{n}}=\beta(\pi-\Sigma) \Sigma,
$$

where $\beta$ and $\pi>0$ are parameters which reflect the level of technical knowledge. Unfortunately Eq. (11) sacrifices the assumption of a technicalprogress function which has first increasing and then decreasing returns, ${ }^{35}$ but it is a practical compromise: it enables us to capture the broad feature of "learning by watching" in the $G_{\mathrm{n}}$ dynamics and, above all, it leads to a differential system which can be analyzed qualitatively.

35 Details are in the quoted King and Robson papers. 


\subsection{The Qualitative Analysis}

By substituting Eq. (10) into Eq. (5), and Eq. (11) into Eq. (7), taking into account Eq. (9), we find the following nonlinear three-dimensional system:

$$
\left.\begin{array}{l}
\dot{G}=\alpha\left\{\left[C^{*}+\varphi\left(G-G_{\mathrm{w}}\right)\right] G_{\mathrm{W}}-\Sigma\right\}, \\
\dot{G}_{\mathrm{W}}=\gamma\left(G-G_{\mathrm{w}}\right), \\
\dot{\Sigma}=\varepsilon\left[\beta(\pi-\Sigma) \Sigma-G_{\mathrm{W}}\right]+\delta \gamma\left(G-G_{\mathrm{w}}\right),
\end{array}\right\}
$$

where, as it has been said above, $\gamma=1 / T \geq 1$ is the speed of $G_{\mathrm{W}}$ adjustment to past $G$ levels.

The system (12) has two singular points ${ }^{36}$ : the origin, i.e., a zerogrowth equilibrium, $P^{(0)}=(0,0,0)$ and a steady-state equilibrium $P^{(*)}=$ $\left(G^{*}, G_{\mathrm{w}}^{*}, \Sigma^{*}\right)$ such that:

$$
G^{*}=G_{\mathrm{w}}^{*}=\frac{\Sigma^{*}}{C^{*}} ; \quad \Sigma^{*}=\pi-\frac{1}{\beta C^{*}} .
$$

Let us note that $G^{*}, G_{\mathrm{w}}^{*}, \Sigma^{*}>0$ if and only if $C^{*}>1 / \beta \pi$. Furthermore, since $\bar{\Sigma}=\pi / 2$ is the saving rate which assures the local maximum of $G_{\mathrm{n}}$, we consider $\Sigma^{*} \leq \bar{\Sigma}$, because in the long run firms' rational behavior cannot imply an investment rate such that $G_{\mathrm{n}}$ should be decreasing.

The usual linearization in a neighborhood of the two critical points yields the following Jacobian matrices:

$$
\begin{aligned}
\mathbf{J}^{(0)} & =\left|\begin{array}{ccc}
0 & \alpha C^{*} & -\alpha \\
\gamma & -\gamma & 0 \\
\delta \gamma & -(\varepsilon+\delta \gamma) & \varepsilon \beta \pi
\end{array}\right| ; \\
\mathbf{J}^{(*)} & =\left|\begin{array}{ccc}
\alpha \varphi G^{*} & \alpha\left(C^{*}-\varphi G^{*}\right) & -\alpha \\
\gamma & -\gamma & 0 \\
\delta \gamma & -(\varepsilon+\delta \gamma) & \varepsilon\left[\beta\left(\pi-2 \Sigma^{*}\right)\right]
\end{array}\right| .
\end{aligned}
$$

Expanding $\left|\mathbf{J}^{(0)}-\lambda \mathbf{I}\right|$ and $\left|\mathbf{J}^{(*)}-\lambda \mathbf{I}\right|$ the following characteristic equations can be obtained:

36 It might be interesting to notice here that, making a comment on Harrod's growth theory, Kalecki (1962) developed a mathematical model by means of quite a different approach, but in a way that two singular points similar to our model are exhibited. 


$$
\lambda^{3}+\alpha_{0} \lambda^{2}+b_{0} \lambda+c_{0}=0
$$

where

$$
\begin{aligned}
& a_{0}=-\operatorname{tr} \mathbf{J}^{(0)}=\gamma-\varepsilon \beta \pi \\
& b_{0}=\gamma\left[\alpha\left(\delta-C^{*}\right)-\varepsilon \beta \pi\right] \\
&=\text { sum of the principal minors of } \mathbf{J}^{(0)}, \\
& c_{0}=-\operatorname{det} \mathbf{J}^{(0)}=\alpha \gamma \varepsilon\left(C^{*} \beta \pi-1\right) ; \\
& \lambda^{3}+\alpha_{1} \lambda^{2}+b_{1} \lambda+c_{1}=0
\end{aligned}
$$

where

$$
\begin{aligned}
a_{1} & =-\operatorname{tr} \mathbf{J}^{(*)}=\gamma-\alpha \varphi G^{*}-\varepsilon \beta\left(\pi-2 \Sigma^{*}\right), \\
b_{1} & =\gamma \alpha\left(\delta-C^{*}\right)-\left(\gamma-\alpha \varphi G^{*}\right) \varepsilon \beta\left(\pi-2 \Sigma^{*}\right) \\
& =\text { sum of the principal minors of } \mathbf{J}^{(*)} \\
c_{1} & =-\operatorname{det} \mathbf{J}^{(*)}=\alpha \gamma \varepsilon\left[C^{*} \beta\left(\pi-2 \Sigma^{*}\right)-1\right] .
\end{aligned}
$$

Assuming $\delta>C^{*}$ and $\alpha\left(\delta-C^{*}\right) \geq \gamma$, it can be shown that these two characteristic equations exhibit a cubic discriminant $\Delta^{3}>0$ if $b>a$. In that case, they possess one real and two complex conjugate eigenvalues. According to the Routh-Hurwitz criterion the equilibria will be locally stable if the following inequalities are jointly fulfilled: $a, b, c>0 ; a b-c>0$.

We can now note that $c_{1}>0$ would imply (taking into account the $\Sigma^{*}$ value)

$$
C^{*} \beta\left(\pi-2 \Sigma^{*}\right)-1>0 \Longrightarrow \frac{1}{\beta \pi}>C^{*},
$$

so that $\Sigma^{*}<0$ and, consequently, $G^{*}=G_{\mathrm{W}}^{*}<0$. Since no economic meaning can be given to a negative steady-state equilibrium, we shall impose $C^{*}>1 / \beta \pi$. In accordance with this inequality it follows that $c_{1}<0$ (i.e., $\operatorname{det} \mathbf{J}^{(*)}>0$ ) implies an unstable steady-state equilibrium. If that is the case, the following Proposition 1 can be demonstrated:

Proposition 1: If $\pi-2 \Sigma^{*} \geq 0$ and $a_{1}>0$, the steady-state equilibrium will be a "saddle focus."

Proof: As $\bar{\Sigma}=\pi / 2$ and $\Sigma^{*} \leq \bar{\Sigma}$, it follows that $\pi-2 \Sigma^{*} \geq 0$. Therefore, if $a_{1}>0$, i.e., $\gamma-\varepsilon \beta\left(\pi-2 \Sigma^{*}\right)>\alpha \varphi G^{*}$, it follows that $b_{1}>a_{1}$, because we assumed ${ }^{37} \gamma \geq 1$ and $\alpha\left(\delta-C^{*}\right) \geq \gamma$. Then, as $c_{1}<0$, the Jacobian matrix $\mathbf{J}^{(*)}$ will have one positive real eigenvalue $\lambda_{1}>0$ and two complex

37 Note that $\gamma=1$ implies $0<a_{1}<1$ and $b_{1} \geq a_{1}$; so that the cubic discriminant will still be positive. 
conjugate eigenvalues $\rho_{1} \pm \omega_{1}$ i. According to Vieta's formula

$$
\begin{aligned}
a_{1} b_{1}-c_{1}= & -\left[\lambda_{1}+\left(\rho_{1}+\omega_{1} \mathrm{i}\right] \cdot\left[\lambda_{1}+\left(\rho_{1}-\omega_{1} \mathrm{i}\right)\right] .\right. \\
& \cdot\left[\left(\rho_{1}+\omega_{1} \mathrm{i}\right)+\left(\rho_{1}-\omega_{1} \mathrm{i}\right)\right]>0
\end{aligned}
$$

after some algebraic rearrangement, it follows that $\rho_{1}<0$. Therefore, the steady-state equilibrium will be a "saddle focus" (Lorenz, 1993, pp. 192200; Glendinning, 1994, pp. 351-358).

Conversely, in the first characteristic equation the parameter $c_{0}$ will definitely be positive, because $C^{*} \beta \pi>1$. So, by assuming $\varepsilon \beta \pi<\gamma$, it follows that $a_{0}>0$ and, consequently, $(0<) b_{0} \geq a_{0}$, because of $\alpha(\delta$ $\left.-C^{*}\right) \geq \gamma$. Therefore, the Jacobian $\mathbf{J}^{(0)}$ will possess one real and two complex conjugate eigenvalues. However, if $c_{0}>0$ ensures a negative real eigenvalue $\left(\lambda_{0}<0\right)$, the sign of the complex conjugate eigenvalues will depend on the sign of the expression

$$
a_{0} b_{0}-c_{0} \lesseqgtr 0
$$

This implies that the equations governing our model have at least one parameter which crucially affects the qualitative properties of the zerogrowth equilibrium. Within the parameters used here to give a new mathematical form to Harrod's model, there is one whose value is objectively ambiguous. This parameter is $\varepsilon$, i.e., the sensitivity of $\dot{\Sigma}$ to the discrepancies between $G_{\mathrm{n}}$ and $G_{\mathrm{W}}$. Our considerations led us to assume $\varepsilon>0$ and specifically an $\varepsilon$ in the neighborhood of unity. However, without some empirical benchmark, it is very difficult to determine the boundaries of this "neighborhood." For this reason we have chosen $\varepsilon$ as a critical parameter for our qualitative analysis.

Therefore, let $\varepsilon^{\prime}$ be an initial value of $\varepsilon$ such that the inequality (15) is positive. Since an increase in $\varepsilon$ implies $\partial a_{0} / \partial \varepsilon<0$ and $\partial c_{0} / \partial \varepsilon>0$, the product $a_{0} b_{0}$ will be equal to zero at a value $\varepsilon=\gamma / \beta \pi$ (because $a_{0}=0$ ) implying that $a_{0} b_{0}-c_{0}=-c_{0}<0$. It follows that there must be a value $\varepsilon^{\prime}<\bar{\varepsilon}<\gamma / \beta \pi$ at which $a_{0} b_{0}-c_{0}=0$. This means that $\bar{\varepsilon}$ is a bifurcation value of our system. In fact, for values of $\varepsilon<\bar{\varepsilon}$ the conjugate pair of complex eigenvalues $\rho_{0} \pm \omega_{0}$ i will have $\rho_{0}<0$; for values of $\varepsilon>\bar{\varepsilon}$ the same eigenvalues will exhibit a real part $\rho_{0}>0$. Given this and taking into account the Hopf bifurcation theorem, ${ }^{38}$ we can state that our system

38 Details can be found in Hale and Koçak (1991), Lorenz (1993), Glendinning (1994), Verhulst (1996). 
possesses closed orbits in a neighborhood of the zero-growth equilibrium, because, for $\varepsilon=\bar{\varepsilon}$, it results $\rho_{0}=0$. But, from the contributions of Coullet et al. (1979), and Arneodo et al. (1982), one can notice that, from a mathematical point of view, our system may be qualitatively compatible with a Šil'nikov (1970) scenario when $\varepsilon>\bar{\varepsilon}$, so that $\rho_{0}>0$.

Under this hypothesis, comparing the two critical points exhibited by our model, we can point out that the sign of the eigenvalues at the zero-growth equilibrium is reversed with respect to that of eigenvalues at the steadystate equilibrium. Therefore, the application of a theorem by Šil'nikov ${ }^{39}$ - as modified by Arneodo et al. (1982, p. 172) and discussed by Tresser (1984, p. 442 and p. 446) - allows us to state that in our system there may exist one orbit $\bar{\Gamma}$, which is asymptotic to one of the two singular points as $t \rightarrow \pm \infty$. Then, being bounded away from the other singularity, if $\bar{\Gamma}$ exists, it will be a homoclinic connection and if $|\lambda|>|\rho|$ every neighborhood of the unstable orbit $\bar{\Gamma}$ will contain a denumerable set of unstable periodic solutions of saddle type. ${ }^{40}$

Next, having numerically verified the existence of $\bar{\Gamma}$, we need to check if the condition $|\lambda|>|\rho|$ is satisfied at least for one of our system singularities. By using the set of parameters reported in Appendix $x^{41}$ and considering $\varepsilon>\bar{\varepsilon}$, the following eigenvalues have been calculated ${ }^{42}$ :

$$
\begin{array}{lll}
\lambda_{0}=-0.73 & \text { and } & \rho_{0} \pm \omega_{0} \mathrm{i}=0.135 \pm 0.799 \mathrm{i} \\
\lambda_{1}=0.347 & \text { and } & \rho_{1} \pm \omega_{1} \mathrm{i}=-0.568 \pm 1.03 \mathrm{i}
\end{array}
$$

So that, according to the Šil'nikov theorem, we can state that our complete model possesses a denumerable set of unstable periodic solutions of saddle type only near the stationary state of zero growth, where $\left|\lambda_{0}\right|>$ $\left|\rho_{0}\right|{ }^{43}$ Figure 1 shows the result of the numerical simulation of our sys-

39 See, for example, Šil'nikov (1970).

40 A full proof can be found in Tresser (1984, pp. 443, 446). See also Glendinning and Sparrow (1984), Wiggins (1990, pp. 573 f.), Heidegger (1991, p. 58). As economic example, see Lorenz (1992).

41 Note that the parameters $\beta$ and $\pi$ have been fixed to give a maximum $G_{\mathrm{n}}$, and consequently a $G^{*}$ value, consistent with the observed rates of growth in the Western economies.

42 Our numerical parameters yield a bifurcation value $\bar{\varepsilon} \cong 0.89362$, while the homoclinic orbit exists for $\hat{\varepsilon} \cong 1.17346$.

43 Note that at the steady-state equilibrium, where $\left|\lambda_{1}\right|<\left|\rho_{1}\right|$, according to a Tresser $(1984$, p. 446) Theorem, there is no periodic orbit in a neighborhood of $\Gamma$. See also Glendinning (1994, pp. 359 f.). 


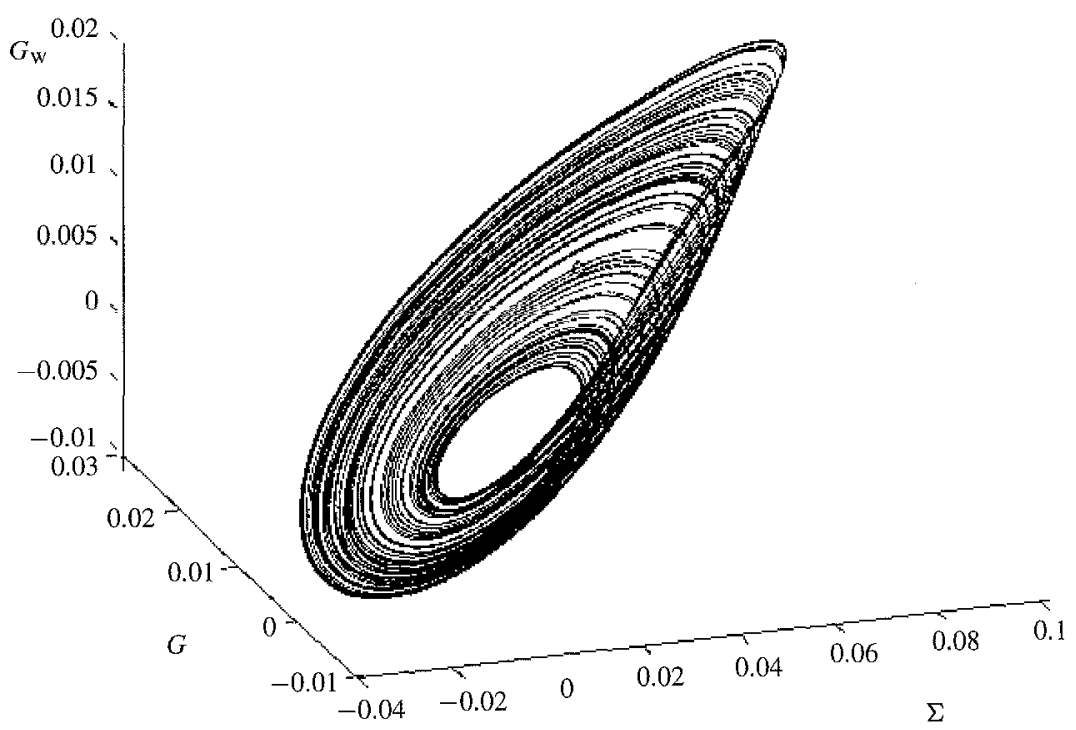

Fig. 1

tem [there initial point coordinates are: $G(0)=0.01 ; G_{\mathrm{W}}(0)=0.008$; $\Sigma(0)=0.03] .{ }^{44}$

The three-dimensional spiral-type object allows us to deduce that every growth path starting from a neighborhood of the origin will move spiralling towards the steady state. Near this point it will be pushed back towards the zero-growth point. When the trajectory reaches this region, again it will start spiralling towards the steady growth and so on. As the trajectory does not pass the initial starting point, in the second round it can differ completely from that in the first round. The trajectory may wander through different points in phase space and may need a longer time before it turns towards a neighborhood of the steady state. As shown in Fig. 2, different initial points imply different trajectories, but the shape of the object remains unchanged. ${ }^{45}$

To confirm our model's chaotic behavior we have calculated the Lyapunov exponents following the computational method suggested by Dieci

44 All the simulations have always been made by using the Runge-Kutta algorithm. In particular, Figs. 1 and 3 have been obtained by means of Matlab 5.3; Fig. 2, by using the Medio and Gallo (1992) DMC software; Figs. 4 and 5, by using Mathematica 3.0.

45 Figure 2 is a projection of the three-dimensional phase portrait onto the $(\Sigma, G)$ plane. Here the geometrical object is the result of 123,420 iterations. The initial point coordinates are: $G(0)=0.02026 ; G_{\mathrm{W}}(0)=0.0203 ; \Sigma(0)=0.1$. 
$\Sigma$

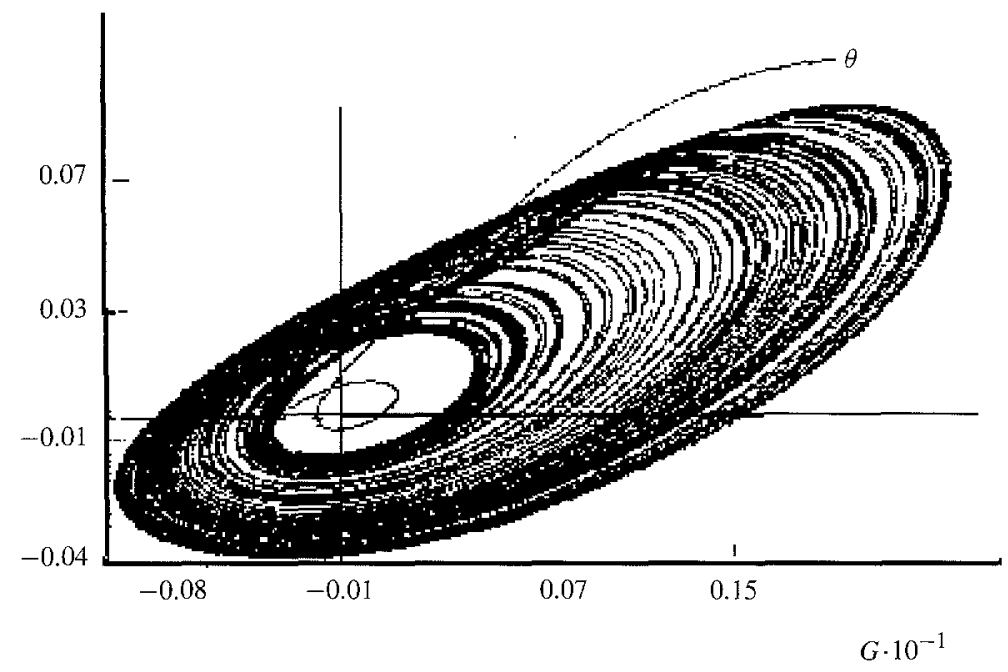

Fig. 2

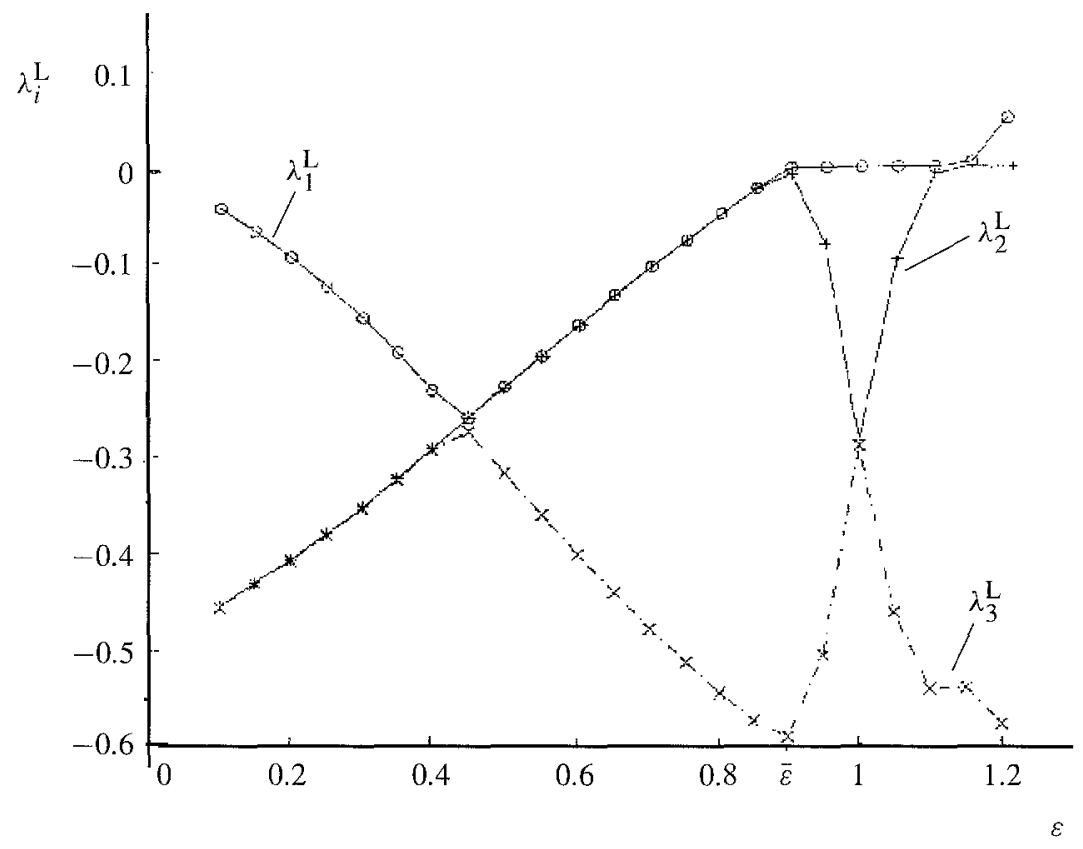

Fig. 3 
et al. $(1995,1996)$. They are: $\lambda_{1}^{\mathrm{L}} \cong 0.049 ; \lambda_{2}^{\mathrm{L}} \cong 0 ; \lambda_{\tilde{3}}^{\mathrm{L}} \cong-0.574$. As the largest characteristic Lyapunov exponent is positive, the motion is chaotic (Lorenz, 1993, p. 218). Furthermore, Fig. 3 shows the relationship between the three Lyapunov exponents and the critical parameter $\varepsilon$. Note that: i) For $\varepsilon<\bar{\varepsilon}$ the Lyapunov exponents are $(-,-,-)$. This implies that an asymptotic stability exists. ii) Near $\bar{\varepsilon}$ the exponents become $(0,-,-)$. This implies the presence of limit cycles. iii) For $\varepsilon>\bar{\varepsilon} \cong 1.17$, one of the exponents becomes positive and a chaotic motion prevails.

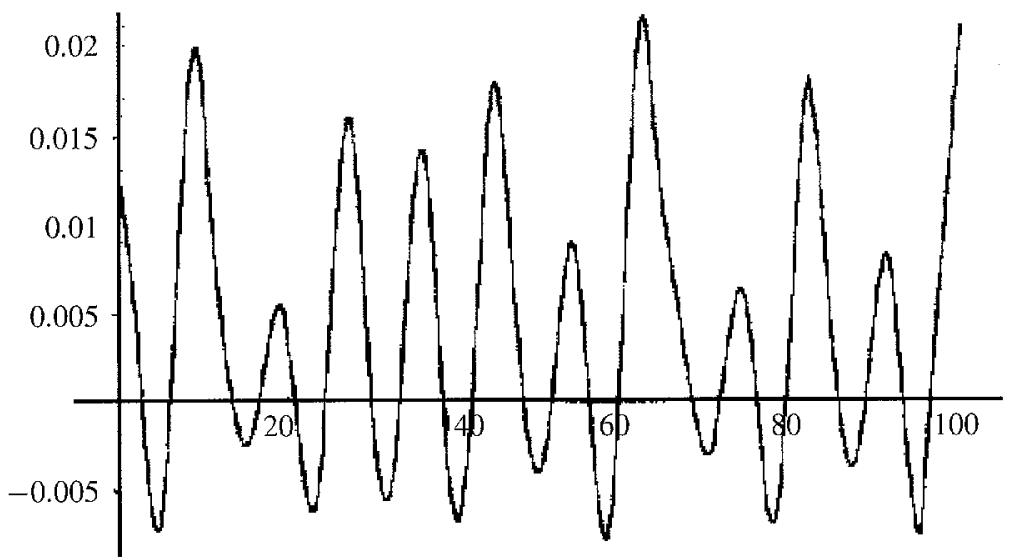

a

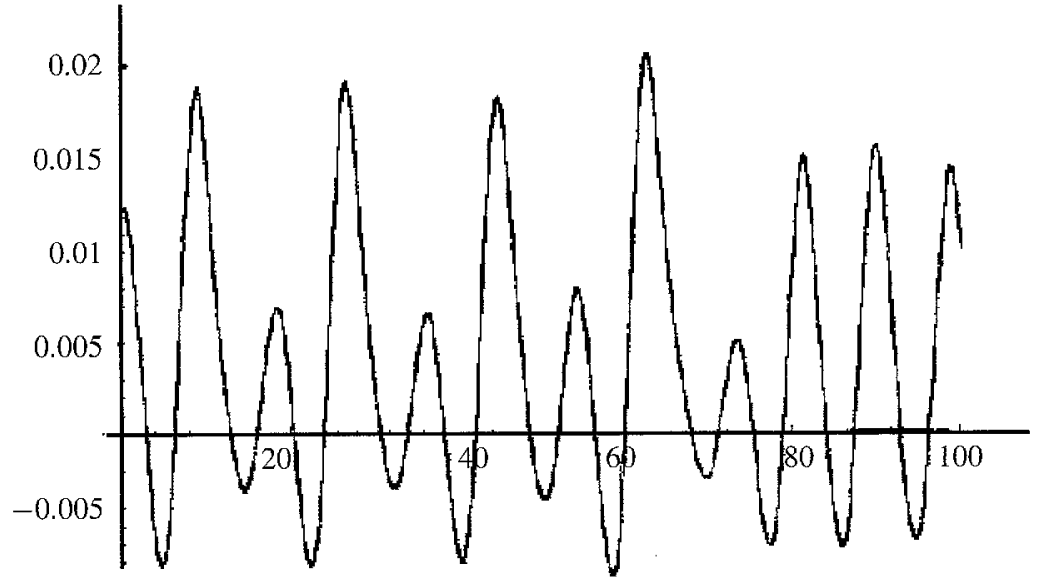

b

Fig. 4. a, Starting point: $G(0)=0.0123 ; W(0)=0.0081 ; S(0)=0.0305$. b, starting point: $G(0)=0.0123 ; W(0)=0.0082 ; S(0)=0.0304$ 
Finally Fig. 4 compares two $G$ time series generated starting from two slightly different initial values. Thus the dependence on initial conditions is evident.

\section{Conclusions}

From a mathematical point of view, given a positive cubic discriminant, we have emphasized an $\varepsilon$ value greater than one in our analysis (specifically, $\varepsilon>\bar{\varepsilon}$ where the homoclinic orbit exists). The formal interest of this case derives from the chaotic motions involving both the steady-state solution (which is often seen as a "goal" by many growth theorists) and the stationary state of zero growth. This is the main analytical result of our model. However, to give this result an economic interpretation, it is important to stress that, whatever the $\varepsilon>0$ value may be, the steady state always remains a repelling singular point. That is, the dynamic trajectories never regularly spiral around the steady state for a few periods, and they are always such that to approach the neighborhood of the steady state on the left-hand side, then, without any way out, they go back toward the origin. This property of the system seems to prevail for all variations in the parameter set consistent with our assumptions. Formally, this means that the range of parameter values which preserve our main economic hypotheses can never be such as to reverse the inequality $c_{1}<0$, because the steady-state solution would become negative and possibly stable if $a_{1} b_{1}-c_{1}>0$. Furthermore, the range of parameter values never may be such as to reverse the inequality $\left|\lambda_{1}\right|<\left|\rho_{1}\right|$. If this were the case, according to the Šil'nikov theorem, some screw-type trajectory might surround the steady growth singularity and only near this point would the trajectory be pushed back towards the origin along the unstable manifold associated with the real eigenvalue $\lambda_{1}$.

Now, if we recall Harrod's theses again, we can state that our theoretical result confirms that the steady-state growth equilibrium is highly unstable. But, at the same time, our mathematical result seems to be in contrast with his view on the cycle. This is regarded by Harrod as "oscillations around a line of steady growth" (Harrod, 1951, p. 261). Instead, looking at Fig. 5, we can realize that our model shows the cycle as an aperiodic motion around the stationary state of zero growth.

Nevertheless, when we draw a $45^{\circ}$ line (where $G=G_{\mathrm{W}}$ ) into the same figure, Harrod's words seem to be well suited to describe our system behavior. "As actual growth departs upwards or downwards from the warranted level, the warranted rate itself moves, and may chase the actual rate in 


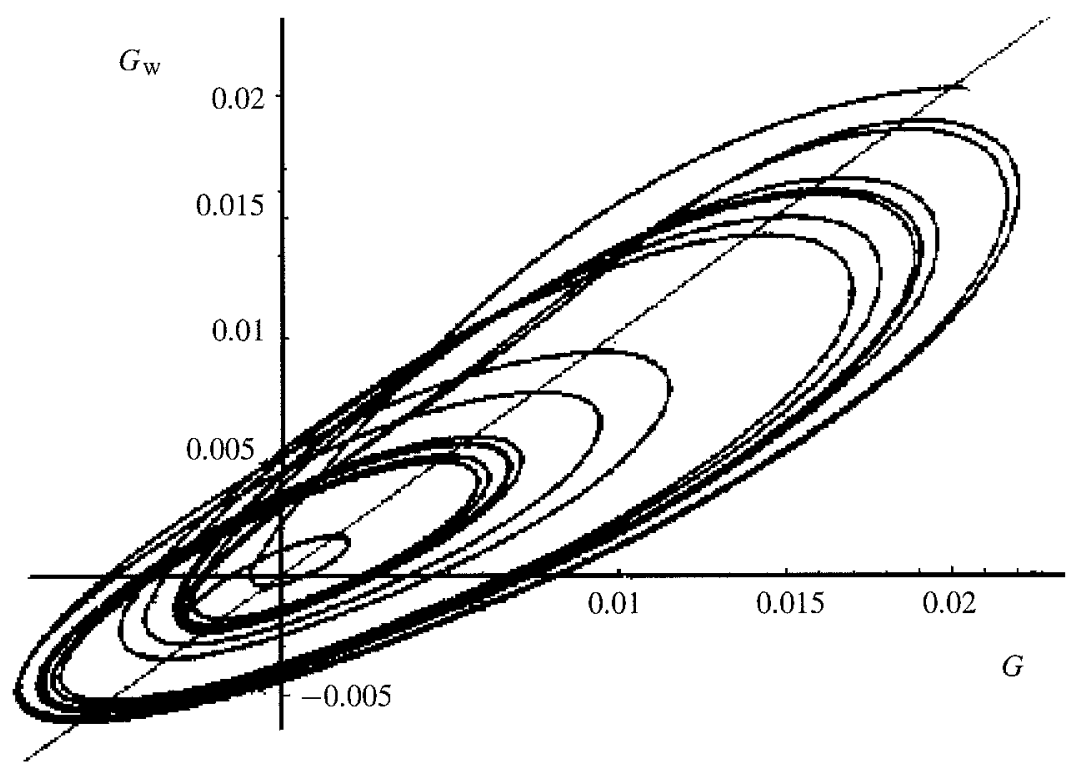

Fig. 5

either direction. The maximum rate of advance or recession may be expected to occur at the moment when the chase is successful" (Harrod, 1939, pp. 28 f.). Furthermore, our model displays negative growth rates near the height of a recession and the savings rate itself becomes negative. Looking on Fig. 2, like Harrod we can say that, the sooner this happens, "the sooner will the slump be arrested" (Harrod, 1996, p. 266). ${ }^{46}$

Are similarities between our analytical results and Harrod's intuitions enough to consider our complete model a faithful interpretation of his dynamic theory? We do not think so, because our results crucially depend on the assumption that the natural rate of growth is endogenous and variable. If we abide by Harrod's hypothesis of an exogenous rate of technical progress, ${ }^{47}$ our model will exhibit a unique singular point: the typical exogenous and unstable steady-state equilibrium. In this case, every Harrodian intuition on the cycle would remain unproved. This confirms that

46 This is a consequence of the assumption that there are no autonomous investments in our model.

47 It might be interesting to recall that Harrod refers to a technical progress meant as a variable in an occasional paper in 1962 (p. 73). Among other things, he writes: "Continuous technological development essentially depends on experience." 
any attempt to put Harrod's theory as a whole into a mathematical framework will give rise either to an under-determined dynamical system, or to a set of dynamical equations able to display only unstable growth equilibria, with explosive motions. To remedy this undesirable quality, Harrod (1973) distinguished normal from special warranted rates of growth. However, similarly to the distinction between normal and abnormal business conditions recently adopted by Pugno (1998), this idea is unacceptable in an analytical context. This is because a model embodying this distinction would be founded on a highly arbitrary component: an approximate rate of growth which acts as discriminant.

Taking note of this conclusion, we have to remind the reader that, in the last decades, the decline of Harrod's style of research is due also to the lack of a true analytical foundation. By providing a new basic interpretation of Harrod's model, our paper sheds new light on the macrodynamic theory inspired by Keynes. Two important results should be stressed in conclusion: i) similarly to the modern growth theory, our model shows that technicalprogress dynamics drive the growth of income; ii) discrepancies between the effective, expected, and technical progress-rates of growth give rise to the cycle, without the need for exogenous shocks.

This last result leads us to recall another quotation from Harrod: "There is, in the real world, no steady advance" (Harrod, 1948, p. 59). However, more properly, we should say, "there is, in a laissez-faire economy, no steady growth."

\begin{tabular}{cll} 
& & \multicolumn{1}{c}{ Appendix } \\
Parameters & $\alpha=0.5$, & $C^{*}=4$, \\
& $\varphi=15$, & $\gamma=1$, \\
& $\varepsilon=1.2$, & $\beta=2.5$ \\
$\pi=0.18$, & $\delta=6 ;$ \\
$\Sigma^{*}=0.08$, & $G^{*}=G_{\mathrm{w}}^{*}=0.02$, \\
$\bar{\Sigma}=0.09$, & $\max G_{\mathrm{n}}=0.02025$.
\end{tabular}

\section{Acknowledgements}

I wish to thank three anonymous referees of this journal and Anton Muscatelli and Daniele Besomi for their helpful comments on a previous draft of this paper. I am also grateful to Nadia Linciano for her useful suggestions and Antonio Gliubich for his contribution to the model's computer simulation. The responsibility for any remaining 
errors is mine alone. This paper is a part of a research programme supported by MURST $60 \%$ funds.

\section{References}

Alexander, S. S. (1950): "Mr. Harrod's Dynamic Model." Economic Journal 60: 724739.

Arneodo, A., Coullet, P., and Tresser, P. (1982): "Oscillators with Chaotic Behavior: an Illustration of a Theorem by Šil'nikov." Journal of Statistical Physics 27: 171-182.

Arrow, K. J. (1962): "The Economic Implication of Learning by Doing." Review of Economic Studies 29: 155-173.

Baumol, W. J. (1948): "Notes on some Dynamic Models." Economic Journal 58: 506521.

(1949): "Formalisation of Mr. Harrod's Model." Economic Journal 59: 625-629.

(1950): "Yet Another Note on the Harrod-Domar Model." Economic Journal 60: $422-427$.

Bean, C. R. (1990): "Endogenous Growth and the Procyclical Behaviour of Productivity." European Economic Review 34: 355-363.

Besomi, D. (1995): "From the Trade Cycle to the Essay in the Dynamic Theory: the Harrod - Keynes Correspondence, 1937-1938." History of Political Economy 27: 309-343.

(1996): "Introduction to An Essay in Dynamic Theory: 1938 Draft by Roy F. Harrod." History of Political Economy 28: 245-251.

(1998a): "Failing to Win Consent: Harrod's Dynamics in the Eyes of his Reader."

In Economic Dynamics, Trade and Growth: Essays on Harrodian Themes, edited by G. Rampa, L. Stella, and A. P. Thirlwall. London: MacMillan.

- (1998b): "Harrod and the 'Time-lag Theories of the Cycle'." In Economic Dynamics, Trade and Growth: Essays on Harrodian Themes, edited by G. Rampa, L. Stella, and A. P. Thirlwall. London: MacMillan.

Chiarella, C., and Flaschel, P. (1996): "Real and Monetary Cycles in Models of KeynesWicksell Type." Journal of Economic Behaviour and Organization 30: 327-351.

Choi, H. (1995): "Goodwin's Growth Cycle and the Efficiency Wage Hypothesis." Journal of Economic Behaviour and Organization 27: 223-235.

Cohen, W. M., and Levinthal, D. A. (1989): "Innovation and Learning: the Two Faces of R\&D." Economic Journal 99: 569-596.

Coullet, P., Tresser, C., and Arneodo, A. (1979): "Transition to Stochasticity for a Class of Forced Oscillators." Physics Letters 72A: 268-270.

Dieci, L., and Van Vleck, E. S. (1995): "Computation of a Few Lyapunov Exponents for Continuous and Discrete Dynamical Systems." Applied Numerical Mathematics 17: 275-291.

Dieci, L., Russel, R. D., and Van Vleck, E. S. (1997): "On the Computation of Lyapunov Exponents for Continuous Dynamical Systems." SIAM Journal of Numerical Analysis 34: 402-423.

Fazzari, S.M. (1985): "Keynes, Harrod, and the Rational Expectation Revolution." Journal of Post Keynesian Economics 8: 66-80.

Flaschel, P., Franke, R., and Semmler, W. (1997): Dynamic Macroeconomics. Cambridge, Mass.: MIT Press. 
Franke, R., and Asada, T. (1994): "A Keynes-Goodwin Model of the Business Cycle." Journal of Economic Behaviour and Organization 24: 273-295.

Glendinning, P. (1994): Stability, Instability and Chaos. Cambridge: Cambridge University Press.

Glendinning, P., and Sparrow, C. (1984): "Local and Global Behaviour near Homoclinic Orbits." Journal of Statistical Physics 35: 645-696.

Glombowski, J., and Krüger, M. (1982): "On Instability Principles in the Context of Growth Cycle Theory." Economic Notes 11: 130-147.

Goodwin, R. M. (1951): "The Non-linear Accelerator and the Persistence of Business Cycle." Econometrica 19: 1-17.

(1967): "A Growth Cycle." In Socialism, Capitalist and Growth, edited by C. H. Feinstein. Cambridge: Cambridge University Press.

Hahn, F. H. (1990): "Solowian Growth Models." In Growth, Productivity, Unemployment, edited by P. Diamond. Cambridge, Mass.: MIT Press.

Hahn, F.H., and Matthews, R.C.O. (1964): "The Theory of Economic Growth: a Survey." Economic Journal 74: 779-901.

Haidegger, W. (1991): "Basic Facts about Homoclinic and Heteroclinic Orbits and their Importance in the Theory of Analytical Chaos." Reports on Mathematical Physics 30: 53-62.

Hale, J. K., and Koçak, H. (1991): Dynamics and Bifurcation. Berlin: Springer.

Harrod, R. F. (1936): The Trade Cycle. Oxford: Clarendon Press.

_ (1939): "An Essay in Dynamic Theory." Economic Journal 49: 14-33.

(1948): Towards a Dynamic Economics. London: MacMillan.

(1951): "Notes on Trade Cycle Theory." Economic Journal 61: 261-275.

(1973): Economic Dynamics. London: MacMillan.

(1996): "An Essay in Dynamic Theory: 1938 Draft," edited by D. Besomi. History of Political Economy 28: 253-280.

Kaldor, N. (1940): "A Model of the Trade Cycle." Economic Journal 50: 78-92.

- (1955/56): "Alternative Theories of Distribution." Review of Economic Studies 23: $94-100$.

_ (1961): "Capital Accumulation and Economic Growth." In The Theory of Capital, edited by F. A. Lutz and D. C. Hague. New York: St. Martin's Press.

Kalecki, M. (1962): "Observation on the Theory of Growth." Economic Journal 72: 134-153.

King, M. A., and Robson, M. H. (1992): "Investment and Technical Progress." Oxford Review of Economic Policy 8: 43-56.

__ (1993): "A Dynamic Model of Investment and Endogenous Growth." In Endogenous Growth, edited by T. M. Andersen and K. O. Moene. Oxford: Blackwell.

Kregel, J. A. (1980): "Economic Dynamics and the Theory of Steady Growth: an Historical Essay on Harrod's Knife-Edge." History of Political Economy 12: 97-123.

Kydland, F. E. (1995): "Business Cycle and Aggregate Labor Market Fluctuations." In Frontiers of Business Cycle Research, edited by T. F. Cooley. Princeton, N.J.: Princeton University Press.

Lorenz, H. W. (1992): "Complex Dynamics in Low-dimensional Continuous-time Business Cycle Models: the Šil'nikov Case." System Dynamics Review 8: 233-250.

- (1993): Non-linear Dynamical Economics and Chaotic Motion. Berlin: Springer. Malley, J., and Muscatelli, V. A. (1996): "Business Cycle and Productivity Growth: Are 
Temporary Downturns Productive or Wasteful?' Discussion Papers in Economics no. 9605, Department of Political Econonmy, University of Glasgow, Glasgow.

Medio, A., and Gallo, G. (1992): Chaotic Dynamics. Cambridge: Cambridge University Press.

Offerman, T., and Sonnemans, J. (1998): "Learning by Experience and Learning by Imitating Successful Others." Journal of Economic Behaviour and Organization 34: $559-579$.

Pasinetti, L. (1962): "Rate of Profit and Income Distribution in Relation to the Rate of Economic Growth." Review of Economic Studies 29: 184-196.

Pugno, M. (1992): Roy F. Harrod: dall'Equilibrio Dinamico alla Instabilità Ciclica. Bologna: Il Mulino.

- (1998): "Harrod's Economic Dynamics as a Persistent and Changing Adjustment Process." In Economic Dynamics, Trade and Growth: Essays on Harrodian Themes, edited by G. Rampa, L. Stella, and A. P. Thirlwall. London: MacMillan.

Romer, P. M. (1986): "Increasing Returns and Long-Run Growth." Journal of Political Economy 94: 1002-1037.

- (1989): "Capital Accumulation in the Theory of Long-Run Growth." In Modern Business Cycle Theory, edited by R. J. Barro. Cambridge, Mass.: Harvard University Press.

(1990): "Endogenous Technological Change." Journal of Political Economy 98: S71-S102.

Rose, H. (1967): "On the Non-Linear Theory of the Employment Cycle." Review of Economic Studies 34: 153-173.

Saint-Paul, G. (1993): "Productivity Growth and the Structure of the Business Cycle." European Economic Review 37: 861-890.

Śil'nikov, L. P. (1970): "A Contribution to the Structure of an Extended Neighbourhood of a Rough Equilibrium of Saddle-focus Type." Mathematical USSR Sbornik 10:91102.

Solow, R. M. (1956): "A Contribution to the Theory of Economic Growth." Quarterly Journal of Economics 70: 65-94.

Stadler, G. W. (1990): "Business Cycle Models with Endogenous Technology." Amer. ican Economic Review 80: 763-778.

Swan, T. W. (1956): "Economic Growth and Capital Accumulation." Economic Record 32: 334-361.

Tresser, C. (1984): "About some Theorems by L. P. Šil'nikov." Annales de l'Institut Henri Poincaré 40: 441-461.

Turnovsky, S. J. (1995): Methods of Macroeconomic Dynamics. Cambridge, Mass.: MIT Press.

Verhulst, F. (1996): Non-linear Differential Equations and Dynamical Systems. Berlin: Springer.

Wiggins, S. (1990): Introduction to Applied Non-linear Dynamical Systems and Chaos. Berlin: Springer.

Addresses of author: Mario C. Sportelli, Dipartimento di Scienze Economiche, Università degli Studi di Bari, Via C. Rosalba, 53, I-70124 Bari, Italy, e-mail: maspo@tin.it; and: Department of Economics, University of Glasgow, A. Smith Building, Glasgow G12 8RT, UK. 